\title{
Prostate Tumor Antigen-activated Autologous Dendritic Cell Vaccine
}

National Cancer Institute

\section{Source}

National Cancer Institute. Prostate Tumor Antigen-activated Autologous Dendritic Cell

Vaccine. NCI Thesaurus. Code C115106.

A dendritic cell (DC)-based cancer vaccine composed of autologous dendritic cells (DCs) activated with a prostate tumor cell lysate containing tumor-associated antigens (TAAs) with potential immunostimulatory and antineoplastic activities. Upon administration, the prostate tumor antigen-activated autologous DC vaccine may stimulate an anti-tumoral cytotoxic T-lymphocyte (CTL) response against prostate cancer cells expressing prostate tumor cell-specific antigens, which may result in prostate tumor cell lysis. 